\title{
Mães e pais pedem melhores escolas públicas ${ }^{1}$
}

á um consenso dentro e fora do Brasil sobre a importância da participação dos pais na vida escolar dos filhos. Ao mesmo tempo, várias pesquisas amplamente difundidas no país têm reportado que os pais de famílias pobres parecem dar pouca importância à qualidade da educação pública dos filhos.

Contudo, uma pesquisa de campo realizada pelo Instituto Fernand Braudel, em 2006, com 1100 famílias na periferia da Grande São Paulo, revelou um segmento significativo de pais pobres que são críticos da qualidade do ensino público.

Para definir melhor essa percepção, o Instituto Fernand Braudel realizou uma pesquisa de campo com 840 pais com filhos matriculados em escolas públicas na cidade de São Paulo, da primeira série do Ensino Fundamental ao último ano do Ensino Médio.

Em entrevistas domiciliares de cerca de 90 minutos de duração, realizadas entre abril e outubro de 2007, buscamos investigar com mais detalhes:

* Nilson Vieira Oliveira é economista (PUC/SP), MBA (BBS) e diplomado pela Escola de Governo/SP. Coordenador e pesquisador do Instituto Fernand Braudel. Tem atuado em pesquisas de campo sobre educação e segurança pública e sobre os avanços nas condições de vida na periferia. É organizador e co-autor de Insegurança pública - reflexões sobre a criminalidade e a violência urbana (Nova Alexandria, 2002). PAtRicia Mota Guedes é mestre em Administração Pública (Universidade de Massachussetts/Amherst) e em Políticas Públicas (Universidade de Princeton). Coordenadora dos programas de Educação e do projeto Círculos de Leitura do Instituto Fernand Braudel. Co-autora de Qualidade na Educação - a luta por melhores escolas em São Paulo e Nova York (Moderna, 2007). Junto com Nilson V. Oliveira, publicou A democratização do consumo na periferia (Braudel Papers, 2006). 
1. as percepções e expectativas dos pais sobre a qualidade da educação de seus filhos e da rede pública em geral;

2. os diferentes níveis e formas de envolvimento na vida escolar dos filhos;

3. suas opiniões e recomendações a respeito de políticas em educação, incluindo temas como progressão continuada, gasto público, avaliação e remuneração diferenciada por desempenho.

Políticos, educadores e lideranças da sociedade civil precisam desenvolver estratégias mais criativas, que reconheçam a diversidade de pais e o potencial, ao menos de um segmento deles, como parceiros em esforços de melhoria da escola pública.

Os dados e depoimentos aqui apresentados são uma parte dos resultados que ilustram o quanto esse potencial ainda é pouco explorado.

Vera Lúcia Santana só consegue ver seus filhos, as gêmeas Pâmela e Grace, 11 anos, e Wendel, 9, de sexta a domingo. Empregada doméstica, 30 anos, moradora da periferia, gastava antes cinco horas por dia no transporte público entre a casa e o trabalho. Agora, dorme de segunda a quinta na casa dos patrões. Mas criou um sistema próprio para acompanhar o estudo dos filhos durante a semana. Ela explica:

Todo dia a gente conversa por telefone sobre o que aconteceu na escola, e eu falo para eles fazerem tudo direitinho.

Quando Vera chega em casa, às dez da noite de sexta-feira, os três filhos estão acordados esperando "para contar o que aconteceu na escola, com o caderninho na mão para mostrar".

As gêmeas Pâmela e Grace estão na sétima série da rede estadual e Wendel, na segunda série de uma escola municipal.

Eu acho que os pais têm que chegar em casa e olhar caderno, conversar sobre o que aconteceu na escola.

Eu sou bem presente com essa história de estudar.

Quando há reunião de pais, Vera Lúcia é liberada do trabalho para participar.

Para ela, acompanhar o que os três filhos estão aprendendo na escola não é fácil.
Políticos, educadores e liderancas da sociedade civil precisam desenvolver estratégias mais criativas, que reconhecam a diversidade de pais e o seu potencial como parceiros em esforcos de melhoria da escola pública.

Realmente o estudo que meus filhos têm eu não tive. Eu não sei se o dever que eles fazem está certo ou errado, mas dá para olhar se a letra deles está perfeita, se fizeram o exercício, conversar com eles, ver as notas e apontamentos no caderno.

Para mães e pais como Vera Lúcia, quem se queixa da falta de interesse e envolvimento dos pais na escola pública precisa conhecer mais de perto histórias como a sua.

\section{Criativos e críticos, apesar da baixa escolaridade.}

Vera Lúcia veio para São Paulo com 16 anos, de Jacaraci, interior da Bahia. Estudou só até a quarta série porque, na zona rural, só havia escola até aí. Sua mãe não concordava que fosse para a cidade continuar os estudos: "Ela achava que mulher não precisava". Como $46 \%$ dos pais entrevistados, não completou o ensino fundamental. A média de escolaridade do total de pais entrevistados é de sete anos, embora $26 \%$ já contem com o ensino médio completo.

No ano passado, Vera soube que seu filho caçula, Wendel, estava com problemas para aprender. A professora mandou um bilhete dizendo que Wendel é inteligente, mas tem preguiça de estudar. Vera concorda que o filho é inteligente e explica:

[...] porque se ele vê uma reportagem na televisão ele sabe me contar, ele se interessa. Mas na escola ele não se interessa por nada.

Preocupada e sem qualquer orientação prática de alguém da escola, Vera Lúcia precisou pensar em algumas estratégias para acompanhar o estudo do filho em casa. Orientou as duas filhas para que acompanhem o que o irmão faz quando volta da escola e fiquem por 
Talvez, experiências como as de Vera expliquem por que $95 \%$ dos pais entrevistados declararam ser contra a progressão continuada. Os depoimentos mostram que o que parece estar por trás de sua forte rejeição não é uma oposição ao conceito de progressão continuada, e sim à forma como tem sido implantada. É uma crítica às baixas expectativas de aprendizagem e ao fracasso escolar, que desperdiçam a curiosidade e o talento de crianças como Wendel.

Vera Lúcia é um exemplo de como já se pode encontrar, na rede pública, um segmento de pais mais críticos. Somente $16 \%$ dos pais disseram que têm seus filhos matriculados na escola pública porque estão satisfeitos com a qualidade do ensino.

Quando perguntados sobre que nota, em uma escala de 0 a 10, dariam à escola de seus filhos, deram 6,5. Para o ensino básico público como um todo, deram 6. Já a nota que dão para as escolas particulares é, em média, 8.

A idade, renda ou gênero não contribuem para que os pais sejam mais críticos em suas notas. Mas, quanto mais anos de escolaridade, mais os pais tendem a dar notas abaixo de 5 para a escola de seus filhos.

Quando analisam a escola de seus filhos, apenas $25 \%$ acha que maioria dos professores não sabe ensinar. Mas há outras críticas mais específicas sobre a escola do filho.

Do total de entrevistados, $31 \%$ reclamam que tanto professores quanto diretores não exigem esforço dos alunos e $54 \%$ acham que os professores não sabem manter a disciplina na sala de aula.

Seja causa, seja efeito da baixa qualidade do ensino, $51 \%$ dos pais acham que a maior parte dos alunos da escola de seus filhos não tem vontade de aprender.

\section{0 papel do professor no aprendizado do filho}

Para Maria Cláudia Ferreira Lima, 33 anos, auxiliar de cozinha, não é certo culpar os pais ou os alunos pelo fracasso escolar. Para ela, quem mais pode fazer diferença é o professor. Maria Cláudia estudou até a oitava série e hoje tem dois filhos, Ingrid, 15, e Michael, 12, em escola pública.

Acha que a escola dos filhos é boa,

[...] mas, como em todo lugar, tem professor que não tem vontade de ensinar.

\section{São relativamente poucos \\ os pais que dão um peso \\ maior ao papel do diretor \\ como líder que pode \\ colaborar na qualidade do \\ ensino.}

Para ela, o problema da baixa qualidade de aprendizado é que

[...] tem professor que está lá na sala de aula por estar, só para ganhar o salário dele.

Conta que ficou chocada quando, na primeira reunião de pais do ano, na escola do filho, os professores disseram aos presentes

[...] que é a mãe que tem que ensinar.

Se a mãe mandou o filho para a escola, é porque ela não sabe ensinar o que a criança precisa aprender na escola. É a professora que tem esse direito [...]

argumenta Maria Cláudia, que planeja voltar a estudar no supletivo à noite, na própria escola dos filhos.

Quando perguntados sobre qual fator mais ajuda um professor a ensinar melhor, os pais se mostraram bem divididos. Enquanto $21 \%$ acha que uma boa formação na faculdade é o mais importante, outros $16 \%$ consideram que seja um bom salário.

São relativamente poucos os pais que dão um peso maior ao papel do diretor como líder que pode colaborar na qualidade do ensino, seja ajudando o professor a resolver problemas na sala de aula ( $8 \%)$, seja exigindo mais de professores e alunos (6\%).

A presença de um assistente para o professor, nas primeiras séries do Fundamental, prática em andamento tanto na rede municipal quanto estadual de São Paulo, foi escolhida por $11 \%$ do total de pais como o fator mais importante, e por $13 \%$ dos pais com filho no ciclo I.

Apesar de críticos sobre a qualidade do ensino, os pais da rede pública têm uma opinião geral de que professores precisam ganhar mais. São altamente favoráveis à remuneração diferenciada por desempenho, com $83 \%$ deles sendo totalmente a favor de uma medida assim. 
Acham que os melhores professores deveriam ganhar em média cerca de 2.450 reais. Esse valor cai para 1.375 reais quando perguntamos o que mereceria ganhar um professor "mediano".

Acham que os professores mais fracos deveriam ganhar não mais de 845 reais - $17 \%$ abaixo do valor médio do que acham ser o salário atual. Mas há pais, como Maria Cláudia, que são ainda mais radicais:

Quanto deveria ganhar um professor fraco? Eu vou falar a verdade para você. Não devia nem ser contratado. Antes de eu dar qualquer salário para um professor, eu queria saber se ele tem vontade de ensinar.

Faz uma pausa e acrescenta:

Se eu fosse governador ou prefeito, eu olharia bem qual é o professor que sabe e gosta de trabalhar.

Maria Cláudia ainda não sabia que, semanas após sua entrevista, o governo do Estado iria passar um decretolei criando um período probatório de três anos para professores concursados. Com a medida, anunciada no final de $\mathbf{2 0 0 7}$, os professores e gestores da rede passam a ser avaliados por três anos em categorias como assiduidade, disciplina, capacidade de iniciativa, comprometimento, eficiência e produtividade, antes de serem efetivados.

Maria Cláudia pergunta se estamos anotando a sua recomendação e continua:

Eu ia avaliar muito os professores. Porque não adianta só dar um salário bom. Nem todo mundo nasceu para ensinar. Nem todo mundo é bom professor.

Mas o que é um bom professor?

Pedimos aos pais que respondessem quais eram os principais atributos de um bom professor, em primeiro, segundo, terceiro e quarto lugares.

- 0 atributo mais importante para $31 \%$ dos pais é explicar de forma que todos entendam.

- Outros 32\% disseram que é tratar o aluno com respeito ou de forma atenciosa.

- Hábitos como "passar bastante dever de casa" ou "passar bastante matéria na lousa" foram citados como mais importantes somente por $13 \%$ e $3 \%$, respectivamente.
- Para a maioria dos pais, o principal motivo que leva alguém a ser professor não é o salário, mas a vocação para ensinar (36\%) ou para trabalhar com crianças e jovens (28\%).

- Somente $16,3 \%$ dos entrevistados acham que o principal fator é a estabilidade no emprego.

- Aposentadoria integral e salário foram citados por $4 \%$ e $5 \%$, respectivamente, enquanto outros $5 \%$ acham que o principal motivo é falta de outras opções.

\section{0 que faz uma boa escola}

Uma escola boa é uma escola com bons professores.

Assim resume Jurandi Pereira da Silva, 38, que se diz muito satisfeito com a escola pública dos dois filhos. Zelador em um prédio na zona oeste, Jurandi veio do sertão de Pernambuco com 18 anos para a periferia norte de São Paulo. "Então brinco que já me naturalizei paulista”, diz, orgulhoso.

E é com orgulho que conta que conseguiu matricular sua filha adolescente, Juliana, em uma escola no bairro da zona oeste onde trabalha, segundo ele, "a melhor da região". A filha ainda mora com a mãe na zona norte, mas Jurandi faz questão de pagar o transporte público. Antes de matricular a filha, ele procurou saber, por meio de amigos e conhecidos, sobre outra escola que fica quase ao lado.

Falaram para eu não colocar nessa outra, quase do lado dessa boa, mas que é totalmente diferente, é mal administrada, tem mau ensinamento, má organização, rola droga, é meio pesado.

Jurandi pode não ter tido acesso a dados de avaliação das escolas para guiar sua escolha, mas não ficou tão longe do apurado em exames como o Exame Nacional do Ensino Médio - Enem e o Sistema de Avaliação de Rendimento Escolar do Estado de São Paulo - Saresp: a escola da filha ficou acima da média da região, enquanto a escola vizinha, tida no boca-a-boca como mais violenta e bagunçada, ficou abaixo da média.

Em uma lista de itens, pedimos aos pais para apontar, do primeiro ao quarto lugar, os atributos de uma boa escola. Chama a atenção como os pais valorizam a qualidade dos recursos humanos da escola e, ao mesmo tempo, como dão relativamente menos valor ao seu próprio papel. 


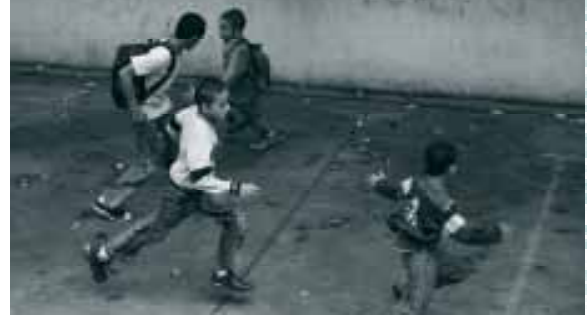

O estereótipo de que pais de escola pública só valorizam infra-estrutura e merenda também precisa ser repensado:

- Para $32 \%$ dos pais, o atributo mais importante é haver professores que saibam ensinar.

- Outros 18,3\% acham que, em primeiro lugar, vem a presença de um diretor exigente.

- A presença de policiamento foi citada por $15 \%$ como a qualidade mais importante.

- Em contraste, apenas $6 \%$ dos pais vêem uma participação mais ativa e exigente dos pais como a característica mais importante de uma boa escola.

- Outros itens como infra-estrutura, material escolar de qualidade, esportes e atividades fora do horário de aula ficaram, cada um, com $5 \%$ da preferência dos pais.

- A merenda escolar só ocupa o primeiro lugar para 1\% dos pais.

Os entrevistados em geral demonstraram alguma familiaridade com exames de avaliação da qualidade de escolas: $69 \%$ disseram conhecer o Enem; $59 \%$, o Saresp; e $34 \%$ sabiam do Prova Brasil e/ou do Sistema de Avaliação da Educação Básica - Saeb.

Praticamente todos $-97 \%$ dos pais - acham importante saber os resultados da escola de seus filhos nessas avaliações. Para metade dos entrevistados, a melhor forma de acessar esta informação seria em reuniões com pais. Outros $27 \%$ preferem receber por correio e $15 \%$, por um comunicado escrito da escola.

A internet só foi citada por 6\%, o que talvez explique em parte o baixo nível de conhecimento de avaliações como o Prova Brasil ou Saeb, cujos resultados podem ser acessados no site do Ministério da Educação.

\section{A participação dos pais na gestão da escola}

\section{Para a maioria dos pais, a principal responsabilidade}

de melhorar o ensino é dos profissionais da escola - professores, gestores ou ambos. Mas há os que acreditam que o envolvimento de pais na gestão escolar pode meIhorar o ensino e passam a participar mais ativamente da administração da escola.

Ainda que minoria, esse segmento de pais precisa ser mais ouvido, compreendido e mobilizado em esforços de reforma do ensino. São lideranças locais, com potencial catalisador, que precisam ser mais aproveitadas pela rede.
É o caso de Conceição Elizabeth Aléo, 52, mãe de César, 12, que faz parte de um grupo de pais, professores e alunos que conseguiram evitar o fechamento de uma escola pública, a E. E. Maximiliano, localizada na Vila Madalena, um bairro de classe alta da cidade.

0 esforço acabou também por atrair o apoio de lideranças e iniciativas do setor privado. Antes, a escola sofria com a perda de alunos, a maior parte, filhos de empregadas domésticas que trabalham na região. Mas, por conta das melhorias que se seguiram à mobilização, a escola já começou a atrair outros pais que não trabalham no bairro e moram em áreas distantes, como o município de Embu, ao sul; o bairro de Itaquera, na zona leste; e até do litoral sul paulista, como São Vicente.

Beth, como Conceição gosta de ser chamada, ressalta que a participação de pais não basta. É necessário contar com a participação dos professores.

Aqui tem vários professores que assumiram a escola, que agarraram com unhas e dentes o trabalho e estão fazendo o melhor pelos alunos.

Beth divide o dia entre o trabalho de voluntária na secretaria da escola e a produção de bijuterias e bolsas para sustentar a família. Membro eleito da APM e do conselho escolar, Beth acha que, apesar de todos os avanços, a participação dos pais ainda deixa muito a desejar.

Você conta nos dedos quantos pais vêm. E olha que aqui pelo menos tem reunião de pais e mestres,

comenta Beth, em alusão à escola anterior do filho, onde precisava cobrar para ficar sabendo quando haveria encontros com pais. Mesmo agora, não acha que as formas de comunicação com os pais são as mais eficientes. Ela questiona:

Os alunos levam um bilhetinho para os pais chamando para a reunião, mas... será que eles entregam?

Beth recorda a primeira reunião com pais da turma do filho César, uma classe com 35 alunos:

Nós estávamos somente em seis pais... E o meu filho é bom aluno, recebi muitos elogios. Mas os pais que têm filho com problema não vieram. Eles não assinam nem boletim. 
A importância de atrair

pais com perfil de liderança para trabalhar

como apoio na equipe

da escola já é uma idéia

que virou política pública

em cidades com grandes

problemas de aprendizado.

Beth também lembra que um dos esforços recentes para atrair os pais incluiu fazer uma reunião no sábado, para aqueles pais que trabalham de segunda a sexta, durante o dia.

Em nossa pesquisa, para $29 \%$ dos pais, o sábado foi apontado como o melhor dia para as reuniões na escola, as quais, por sua vez, tradicionalmente, ocorrem durante a semana, no horário em que seus filhos estudam.

Gestores que se entusiasmem com esta demanda não atendida precisam saber, alerta Beth, que mesmo reuniões aos sábados não vão garantir um grande contingente.

O trabalho de Beth Aléo na escola do filho pode ser voluntário, mas já se tornou uma função essencial na opinião de professores e da direção. Mesmo com a baixa participação dos responsáveis nas reuniões de pais, da APM e do Conselho Escolar, há muito que pode ser feito em pequenos grupos, aproveitando pais com potencial de liderança como Beth.

A importância de atrair pais com perfil de liderança para trabalhar como apoio na equipe da escola já é uma idéia que virou política pública em cidades com grandes problemas de aprendizado, como Nova York. Lá, o prefeito Bloomberg criou a posição remunerada de "coordenador de pais", baseando um coordenador em cada escola da rede. Esses coordenadores, recrutados entre pais do bairro, funcionam como intermediários entre profissionais da escola e pais de alunos, auxiliando a diminuir o abismo entre eles, especialmente nas comunidades mais pobres da cidade.

Beth mostra a lista de sugestões para políticos e secretários de educação que preparou para a entrevista. Uma de suas recomendações é que as escolas tenham um sistema de supervisão "que venha em defesa das crianças que, ao contrário do meu filho César, não têm pais que podem cobrar mais qualidade".

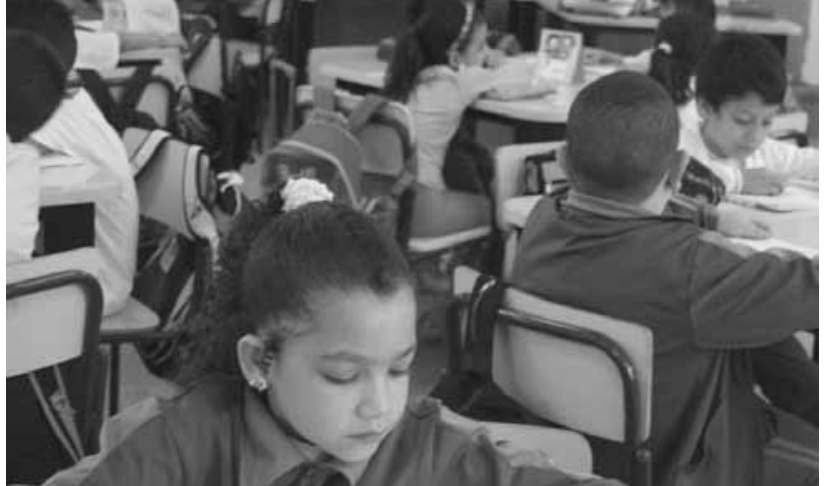

\section{Supervisão e avaliação}

\section{Envolvida na organização da próxima reunião da APM,}

Beth precisa interromper a entrevista para fazer ligações para pais, reforçando com eles o convite e a pauta do próximo encontro.

Com o caderno na mão, faz questão de acrescentar que não são somente os pais que deveriam vir mais às escolas de seus filhos, "os secretários de educação e supervisores de ensino também". Mas com uma condição: precisam vir sem aviso prévio, para pegar a escola de surpresa. E explica:

Eles deviam chegar assim de surpresa, porque, se avisam, é tudo muito arrumado, muito organizado, muito "olha, meninada, o Sr. Fulano vai vir aqui amanhã, não quero papel jogado no chão, não quero barulho nem confusão".

Erli Rodrigues da Silva, 49, como Beth, também sente falta de um olhar externo que avalie e acompanhe 0 trabalho nas escolas. Coordenadora de uma entidade de bairro, na periferia sul de São Paulo, que distribui leite e oferece atividades fora do horário escolar para as crianças do entorno, Erli é mãe de dois filhos na rede pública.

\footnotetext{
Eu noto que mesmo aqueles programas das Secretarias de Educação que são dirigidos à escola não funcionam porque não tem uma fiscalização, um responsável de fora. Eu vejo que os professores deveriam ter uma cobrança maior atrás deles, alguém que fosse o gestor de tudo que acontece na sala de aula, que pudesse acompanhar de perto o trabalho do professor.
}

Para Erli, a direção da escola não dá conta de melhorar o ensino. Mas ressalta que é preciso haver alguém com autoridade para entrar na sala de aula, seja para ajudar, seja para cobrar mais do professor. Erli compara a autoridade dos professores à de juízes de futebol:

Quando o juiz está dentro de campo, o espaço é dele, pode descer Deus do céu e entrar ali dentro porque Deus não vai mandar. Se o juiz errou, ninguém vai tirar um gol, o que ele falou, está falado. Assim é o professor na sala de aula. Ninguém manda ou pode interferir no que ele faz lá dentro. 


\section{Acompanhamento da aprendizagem dos filhos}

\section{Sem um sistema de supervisão mais eficiente e ain-} da sem um acesso fácil a resultados de avaliações externas por escola e por aluno, verificar o boletim é, ao menos por enquanto, a prática utilizada por mais pais $82 \%$ dos entrevistados - para acompanhar o aprendizado dos filhos.

Em contrapartida, somente $53 \%$ tem o hábito de corrigir ou revisar as lições feitas pelos filhos. Há outras estratégias citadas, como examinar o número de trabalhos escolares exigidos pelos professores $(71 \%)$ e as anotações ou correções do professor no caderno (70\%).

Outra estratégia muito utilizada por $57 \%$ dos pais é a de olhar a quantidade de dever de casa. Pais com fiIhos no Ciclo I do Fundamental se utilizam de um número maior de formas de acompanhamento do aprendizado dos filhos. A tendência é de um menor envolvimento no Ciclo II, e menor ainda no Ensino Médio. E 74\% do total de entrevistados diz utilizar muito a estratégia de observar o que os filhos contam que aprenderam na escola.

Já vimos que a maior parte dos pais não acha que a quantidade de exercícios seja o principal indicador de um bom professor, mas verificar os cadernos dos filhos para ter uma idéia do que ocorre na sala de aula é ainda uma das estratégias mais usadas para acompanhar a vida escolar do filho, especialmente no Ensino Fundamental.

É o caso de Edna Maria de Oliveira Gomes, 36 anos, de Pesqueira, Pernambuco. Diarista, Edna cursou até a sexta série.

Meu marido que veio primeiro, falta de emprego, essas coisas, aí ele veio, arrumou emprego, depois mandou me buscar.

Costuma checar três ou mais vezes por semana o caderno dos filhos, Diego, 14, e David, 10.

No meio do ano, o David não tinha nada de lição feita no caderno. Aí ele falou que era a professora que não estava ensinando, ele falou: “ó, mãe, a professora chega lá e fica jogando joguinho no celular”.

O filho gostava da professora porque "ela falou para a turma que eles podiam bagunçar, que ela não estava nem aí, estava ganhando o seu salário todo mês". Apesar da indignação, Edna não foi reclamar da escola. "Eu ia combinar com as mães para tirar as professoras de lá”, lembra, mas, antes do final do semestre, a professora saiu e

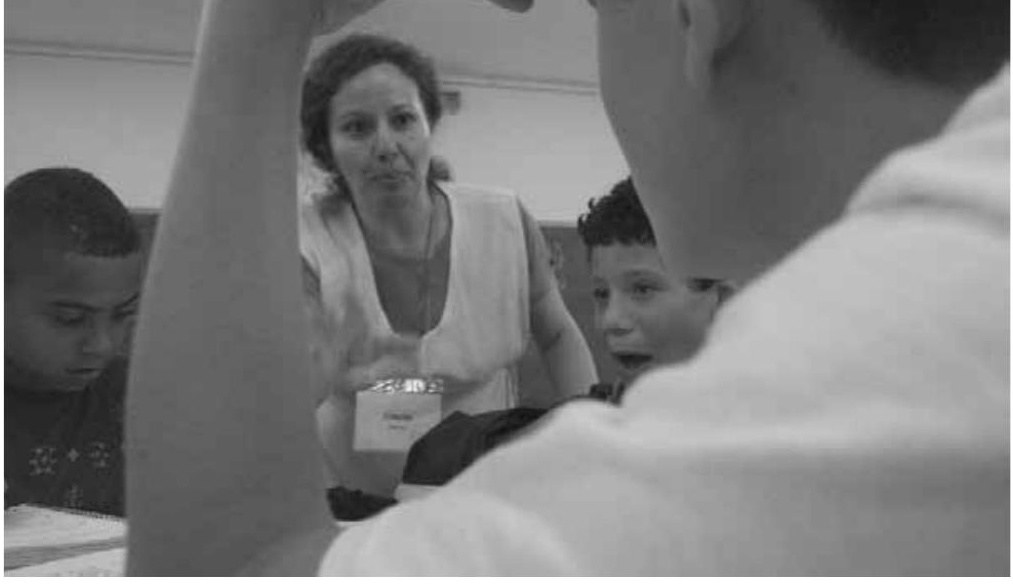

foi substituída por outra, na opinião de Edna, "muito meIhor, graças a Deus".

O absenteísmo de professores, outro problema muito citado tanto por secretários de educação como por outros gestores, chega ao conhecimento dos pais por meio dos próprios filhos. Sidilene Carvalho Rocha, 40, conta que tem o costume de perguntar ao filho Diogo, que está na sétima série, como foi a aula. É assim que soube do problema de faltas dos professores. Ela conta:

Pelo menos onde meu filho está estudando, todos os dias ele me conta que faltou um professor e nem sempre tem substituto.

Sidilene sempre vai às reuniões de pais, mas não conseguiu ainda ver o problema resolvido. Ela reclama também da qualidade das aulas dos substitutos:

Muitas vezes eles colocam uma matéria na lousa e não explicam, os alunos saem da aula sem saber.

\section{Absenteísmo e carência de professores}

\section{Quase metade - $\mathbf{4 5 \%}$ - dos pais disse que a escola do}

filho sofre de falta de professores. Porém, quando perguntados sobre os motivos e a freqüência de aulas vagas por causa de falta de professores, os pais mostraram um conhecimento apenas parcial do problema. Isso talvez se deva, em parte, porque, mesmo com aulas vagas, os alunos permanecem na escola, no pátio ou na sala de aula, muitas vezes fazendo barulho e desordem que atrapalham outras turmas.

- Para os pais, o número máximo aceitável de faltas para professores por ano deveria ser de seis dias, com quase nenhuma diferença entre os níveis de ensino.

- Pouco menos de $14 \%$ dos pais disseram que os professores nunca poderiam faltar e cerca de metade (48\%) disse que o aceitável seria somente entre um e cinco dias de faltas por ano. 
- Apenas $12 \%$ dos pais acham que professores devem faltar mais de 10 dias por ano.

Os pais entrevistados estimam que a escola dos filhos perde, em média, 4,6 dias de aula no ano por causa de faltas de professor, chegando a sete dias para alunos do Ensino Médio. Mas a Secretaria de Educação do Estado, por exemplo, estimou que os professores faltam em média 32 dias letivos por ano.

Quase 30 mil, dos 230 mil professores da rede estadual de ensino paulista, faltam às aulas diariamente, segundo dados oficiais de 2006. Dos 30 mil, menos de 2.400 têm faltas que acarretam perda de salário. Naquele ano, o absenteísmo de professores custou $235 \mathrm{mi}$ Ihões de reais aos cofres públicos em pagamento de professores substitutos.

$\mathrm{Na}$ rede municipal, o problema é semelhante. Com cerca de 50 mil docentes, a rede sofreu, somente de janeiro a agosto de 2007, 97,4 mil faltas sem perda de salário e outras 11,9 mil que acarretaram perda de vencimento.

Gratificações por assiduidade, tanto na rede estadual quanto na rede municipal, ainda não conseguiram resolver o problema.

A principal recomendação apontada para coibir as faltas de professores é o desconto no salário, para 34\% dos entrevistados.

Outros $31 \%$ acham que a primeira medida deveria ser uma advertência e $19 \%$ acham que professores faltosos deveriam ter um desconto no seu tempo de férias. Se os pais de escolas públicas fossem comunicados, pela escola ou pela Secretaria de Educação, sobre exatamente quantas aulas seus filhos perdem por causa da falta de professores, talvez sua insatisfação fosse ainda maior.

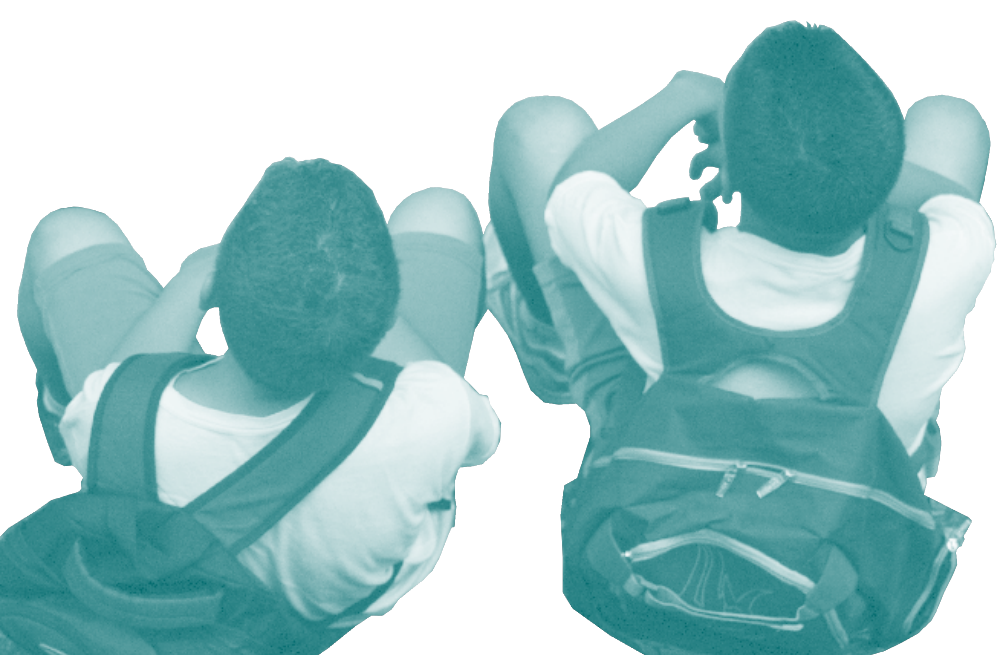

\section{Os resultados dessa pesquisa demonstram que os pais}

de alunos das escolas públicas não podem mais ser representados como uma massa homogênea, sem senso crítico e totalmente satisfeitos com a qualidade da escola. Há segmentos de pais mais críticos e interessados que precisam ser reconhecidos como aliados pelas escolas e secretarias de educação.

Não se deve esperar que a totalidade ou a maioria dos pais consiga ou saiba como melhor se envolver com a escola dos filhos. Tampouco que todos possam exercer pressão política pelas reformas necessárias. No entanto, existe uma parcela de pais que só espera uma oportunidade e uma maior abertura das escolas para assumir o papel que lhes for possível. São uma liderança em potencial para estimular esforços de reforma do ensino, apoiando medidas arrojadas, como a remuneração por mérito e a avaliação externa do aprendizado.

Esses pais compreendem que são poucas ou nulas as chances de mobilidade social de seus filhos no futuro, se prosseguirem numa escola pública fracassada.

Eles precisam ser mais ouvidos e incluídos na formulação e implantação das políticas públicas de educação.

\section{NOTA}

1 Esta pesquisa com pais de alunos das escolas públicas de São Paulo faz parte do programa Reforma do Ensino Público, conduzido pelo Instituto Fernand Braudel de Economia Mundial desde 2007. A pesquisa foi uma parceria do Instituto Fernand Braudel com a Fundação Victor Civita e também contou com o apoio operacional do Instituto de Pesquisas Estatísticas da Universidade de São Caetano do Sul. Gráficos e tabelas da pesquisa estão disponíveis no site: 〈www.braudel.org.br〉. 